\title{
Effectiveness and safety of the surgical closure of permeable arteriosus conduct by the general pediatric surgeon: Clinical trial
}

\author{
Eficacia y seguridad del cierre quirúrgico del conducto arterioso permeable por el \\ cirujano pediatra general: ensayo clínico
}

\author{
Antonio F. Gallardo-Meza', José M. González-Sánchez', Francisco Vidrio-Patrón', \\ Irene L. Velarde-Briceño ${ }^{1}$, Alejandra Peña-Juárez², Humberto Murguía-Guerrero', \\ María Teresa Martínez-González³, Oscar E. Ceja-Mejía ${ }^{4}$, Miguel A. Medina-Andrade1, \\ Paulina Armas-Quiroz ${ }^{4}$, Brenda N. Arias-Uribe ${ }^{4}$, Elizabeth López-Villalobos ${ }^{4 *}$, and \\ Humberto Vázquez-Jackson ${ }^{1}$
}

${ }^{1}$ Department of Pediatric Surgery; ${ }^{2}$ Department of Pediatric Cardiology; ${ }^{3}$ Department of Pediatrics; ${ }^{4}$ Neonatal Intensive Care Unit. Hospital General de Occidente, Hospital Santa María Chapalita, Guadalajara, Jalisco, Mexico

\begin{abstract}
Background: The patent ductus arteriosus (PDA) is congenital heart defect and is considered a public health problem. It occurs in a high percentage of newborns (NBs) and in some older than 1 month. Pharmacological closure is the preferred initial treatment, as it has had excellent results; however, in those cases where it is not possible, surgical closure is indicated. Objective: The objective is to evaluate the efficacy and safety of the surgical closure of the patent PDA when it is carried out by pediatric surgeons without specialization in cardiovascular surgery. Methods: This study was conducted at the West General Hospital, a $2^{\text {nd }}$ level public hospital, with the diagnosis of PDA that required surgical correction. For the collection of the information, the files from January 2001 to December 2018 were retrospectively reviewed. Results: Two hundred and twenty-four patients were included; divided into two groups: Group I: 184 (82\%) "NBs" and Group II: 40 (18\%) "big children" with ages from 2 months to 8 years. All had a surgical closure; three by thoracoscopy and 221 by left posterolateral thoracotomy. Thirty-six patients presented complications representing $16 \%$ of the total of patients, only $5.3 \%$ were major complications. Twenty-four patients died in the post-operative period, representing a mortality of $10.7 \%$, none died due to trans-surgical complications. PDA is a congenital heart defect that occurs in a high percentage of premature patients. The pharmacological closure is the principal treatment because it has had excellent results in NBs; however, in those cases where it is not possible, surgical closure it's indicated. All patients were operated by general pediatric surgeons, with a global survival of $92 \%$. Conclusions: We conclude that in hospitals where there is no pediatric cardiovascular surgeon or interventional cardiologist, the surgical correction of the PDA can be carried out by a general pediatric surgeon. The technique is reproducible, easy to perform and with minimal complications.
\end{abstract}

Key words: Ductus arteriosus. Premature birth. Surgical treatment.

Correspondence:

*Elizabeth López Villalobos

E-mail: lizylovi@ hotmail.com

2604-7063 / @ 2020 Instituto Nacional de Cardiología Ignacio Chávez. Published by Permanyer. This is an open access article under the CC BY-NC-ND license (http://creativecommons.org/licenses/by-nc-nd/4.0/).
Date of reception: 22-01-2020

Date of acceptance: 21-08-2020
Available online: $25-05-2021$

Arch Cardiol Mex (Eng). 2021;91(1):65-74 www.archivoscardiologia.com 


\section{Resumen}

Antecedentes: El conducto arterioso permeable $(C A P)$ es un defecto cardiaco congénito y se considera un problema de salud pública. Se presenta en un alto porcentaje de recién nacidos y en algunos mayores de 1 mes. El cierre farmacológico es el tratamiento inicial preferido, ya que ha tenido excelentes resultados; sin embargo, en aquellos casos en los que no es posible, está indicado el cierre quirúrgico. Objetivo: Evaluar la eficacia y la seguridad del cierre quirúrgico del CAP por cirujanos pediatras sin especialidad en cirugía cardiovascular. Método: Ensayo clínico realizado en pacientes del Hospital General de Occidente, centro hospitalario público de segundo nivel, con diagnóstico de CAP, que requirieron corrección quirúrgica. Se revisaron en forma retrospectiva los expedientes de enero de 2001 a diciembre de 2018. Resultados: Se incluyeron 224 pacientes divididos en dos grupos: grupo I, con 184 (82\%) recién nacidos, y grupo II, con 40 (18\%) niños grandes de 2 meses a 8 años de edad. A todos se les realizó cierre quirúrgico: 3 por toracoscopía y 221 por toracotomía posterolateral izquierda. Presentaron complicaciones 36 pacientes, lo que representa el 16\% del total; solo el 5.3\% fueron complicaciones mayores. Fallecieron 24 pacientes en el posoperatorio, lo que representa una mortalidad del 10.7\%; ninguno falleció por complicaciones transquirúrgicas. EI CAP es un defecto cardíaco congénito que se presenta en alto porcentaje en pacientes prematuros. El cierre farmacológico es el principal tratamiento por tener excelentes resultados en recién nacidos; sin embargo, en aquellos casos en los que no sea posible está indicado el cierre quirúrgico. Todos los pacientes fueron operados por cirujanos pediatras generales, con una sobrevida global del 92\%. Conclusiones: En los hospitales donde no hay cirujano cardiovascular pediátrico ni cardiólogo intervencionista, la corrección quirúrgica del CAP puede ser llevada a cabo por un cirujano pediatra. La técnica es reproducible, fácil de realizar y con mínimas complicaciones.

Palabras clave: Conducto arterioso permeable. Recién nacido prematuro. Tratamiento quirúrgico.

\section{Introduction}

Patent ductus arteriosus (PDA) is the congenital heart disease that occurs more frequently in premature newborns (NBs). It is the most common among congenital heart defects ${ }^{1-4}$, and it affects one out of every 5000 full-term NBs ${ }^{5}$. Overall incidence in premature NBs, it is $50-70 \%$, and it can affect up to $80 \%$ of very low-weight $(<1000 \mathrm{~g})$ preterm NBs ${ }^{6-8}$. It is closely related to morbidity and mortality in premature NBs, and it is, therefore, considered a major public health problem.

NBs with the highest risk of PDA are those who develop respiratory distress syndrome (RDS), transient tachypnea of the newborn (TTN), intrauterine pneumonia, meconium aspiration syndrome or persistent pulmonary hypertension of the $\mathrm{NB}^{6-8}$. Diagnosis based only on clinical data is difficult, since signs and symptoms can be confused with some respiratory problems of the NB or with septicemia, which makes for the diagnosis of hemodynamically significant PDA (hs-PDA) to be late.

Neonatal intensive care units are increasingly successful in premature patient's survival. This is because non-invasive heart disease diagnosis with portable Doppler echocardiography equipment is easily accessible to these units. Thus, PDA early diagnosis has significantly increased.

A PDA diameter $>1.5 \mathrm{~mm}$, with a pulmonary flow/ systemic flow ratio $>1.5$, is a highly predictive indicator that the PDA is not going to close and, therefore, a high percentage of these cases will develop hs-PDA, which allows treatment decisions to be early made. At present, the treatment of choice is pharmacological closure, with good results in different studies. However, in case this type of closure is not achieved, percutaneous closure by catheterization can be carried out by an interventional cardiologist or surgical closure with thoracotomy by a pediatric cardiovascular surgeon ${ }^{9-15}$. In this study, we show our results with PDA surgical closure in those patients who failed to respond to pharmacological closure or who had any contraindication for it.

There are no publications comparing success or failure rates in PDA closure performed by a pediatric general surgeon in comparison with a pediatric cardiovascular surgeon ${ }^{16}$.

The purpose of this work is to demonstrate that PDA surgical closure can be successfully carried out by pediatric surgeons with no specialty in cardiovascular surgery, which facilitates the management of the most common congenital heart disease. The reason is the lack of a pediatric cardiovascular or interventional surgery department in secondary and tertiary care hospitals in Mexico, as well as in many countries similar to ours.

\section{Method}

Descriptive study in which PDA patients were analyzed, with special attention to surgical closure and its 
evolution, complications, and mortality. It was carried out at Hospital General de Occidente, a secondary care public hospital center that provides healthcare to pediatric open population.

The inclusion criteria were having a diagnosis of PDA requiring surgical correction. Patients without complete medical records were excluded from the study. For the collection of information, medical records were retrospectively reviewed from January 2001 to December 2018 , which entailed a total of 227 PDA surgical closures. Two-hundred and twenty-four complete records were found; the rest, three patients, did not have a complete record, or it was already purged and, thus, they were excluded from the study.

The reviewed variables included gender, gestational age, reason for admission, drug treatment, age and weight at the time of surgery, type of approach, surgical time, pulmonary hypertension assessment, failure to extubate the patient, extubation time after surgery, complications, and mortality.

Of the study population, patients were divided in two groups (Fig. 1):

- Group I: NBs of 24.1-41 weeks of gestational age.

- Group Il: older children, which included patients aged from 2 months to 8 years.

Group I patients were admitted to the neonatal intensive care unit for prematurity and any associated problem: respiratory (RDS or TTN), neonatal sepsis, neonatal hypoxia, and asymmetric malnutrition or others. Group II patients were admitted for clinical data consistent with hemodynamic repercussion, failure to thrive or frequent respiratory infections, and during their diagnostic approach, PDA was found.

Patients included in the closure protocol were those with clinical and echocardiographic data consistent with hs-PDA. Clinical data included oxygen dependence, respiratory deterioration, extubation failure, increased mechanical ventilation parameters requirement, hemodynamic decompensation, and target organs hypoperfusion (acute kidney failure or necrotizing enterocolitis). Doppler echocardiogram data considered at the time of the study included the presence of a duct with a diameter $>1.5 \mathrm{~mm}$ and pulmonary flow/systemic flow ratio $>1.5$. Left atrium/ aorta ratio $>1.5$ should also be considered with added data such as descending aorta diastolic steal.

Patients within the closure protocol were divided in two groups:

- Group A: patients initially undergoing pharmacological closure with cyclooxygenase inhibitors or prostaglandins (or both); if there was no echocardiographic response, patients underwent surgical closure.

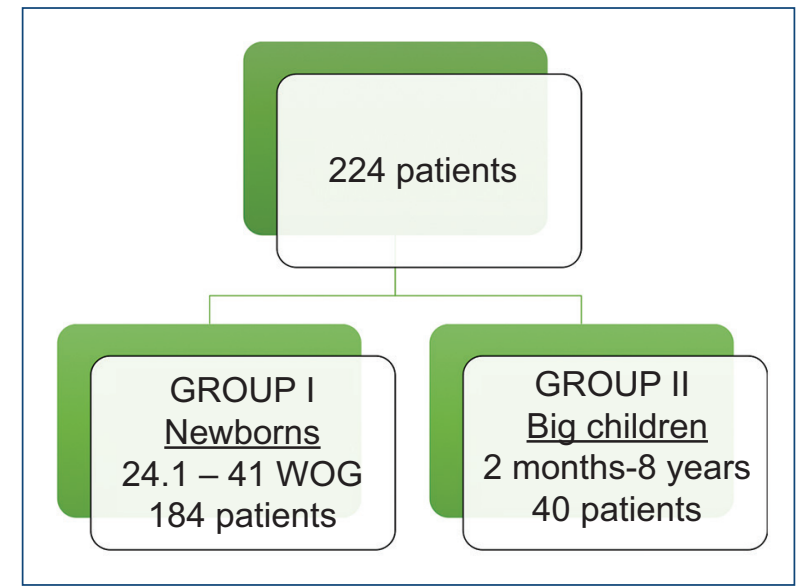

Figure 1. Distribution by age. WOG: weeks of gestation.

- Group B: patients with any contraindication to pharmacological closure who went on directly to surgical closure.

The surgical technique used in patients of both groups was left posterolateral thoracotomy, with initial extrapleural approach, and in case of pleural tear, it is intrapleurally completed. The duct is identified taking as a primary reference the vagus and recurrent laryngeal nerves, dissection is carefully made in its entire diameter and 3-0 or 4-0 double silk ligation is made without duct section in Group I patients, and with section and suture in Group II patients. With the extrapleural approach, pleural tube was not left; with the intrapleural, a pleural tube was left for $24 \mathrm{~h}$.

In thoracoscopic cases, the approach is with three 3-mm ports: posterior clavicular line, fifth intercostal space, through which optics is introduced, and under direct vision, other two ports are inserted, one in the posterior clavicular line seventh or eighth intercostal space, and the other in the midclavicular line seventh intercostal space. An intrapleural approach is made and the duct is ligated with a $5-\mathrm{mm}$ Hemolock staple, leaving an intrapleural tube for $24 \mathrm{~h}$ (Fig. 2).

Approval for the surgical procedure was obtained by means of informed consent, signed by the patients' legal representatives.

\section{Results}

Of the 227 operated patients, 224 with complete records were included and divided in two groups (I and II) according to age. In Group I, there were 184 patients (Fig. 3). Group I patients reason for being admitted to the neonatal intensive care unit was prematurity and 


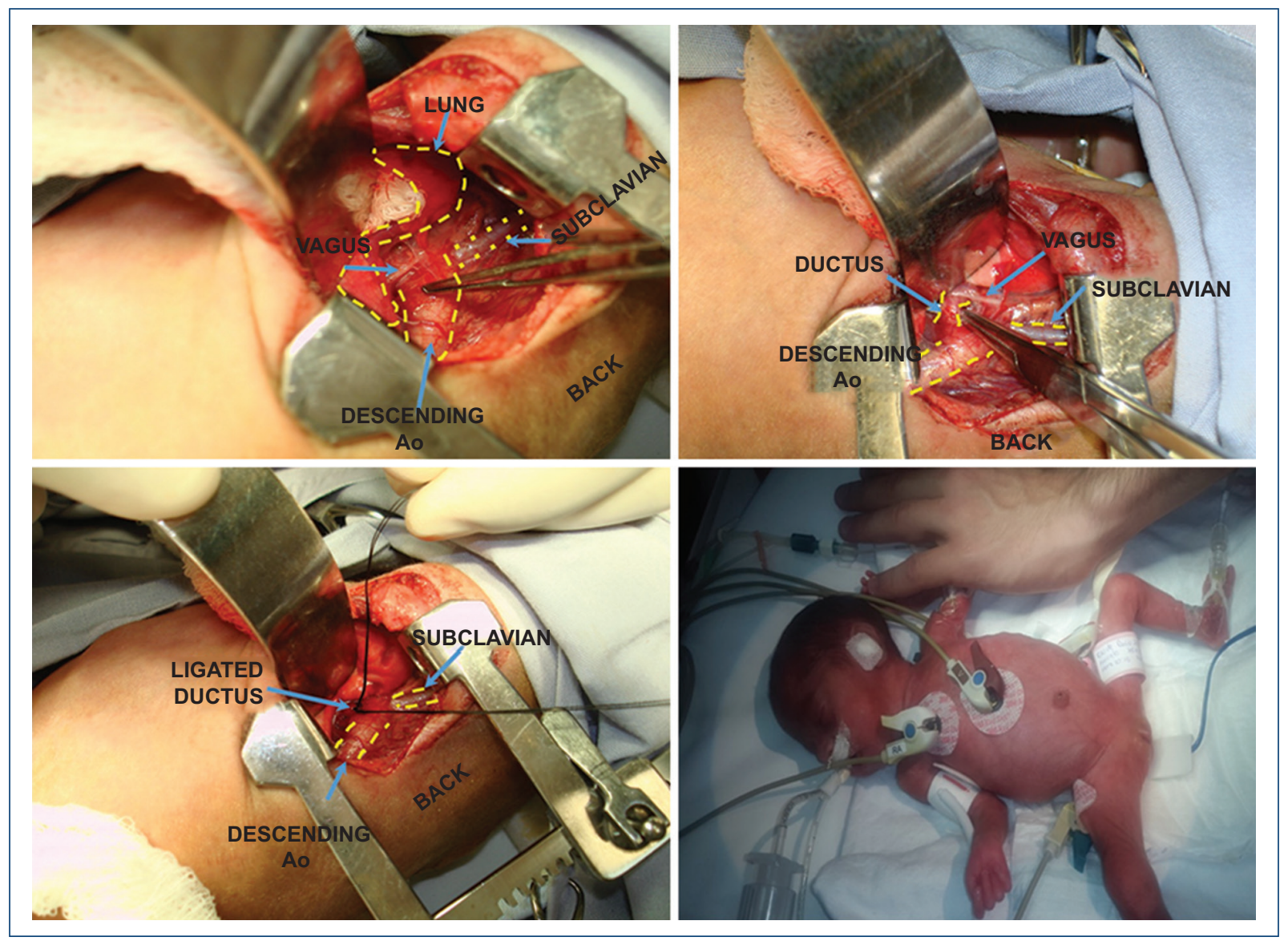

Figure 2. Pictures of the surgical technique. Ao: aorta

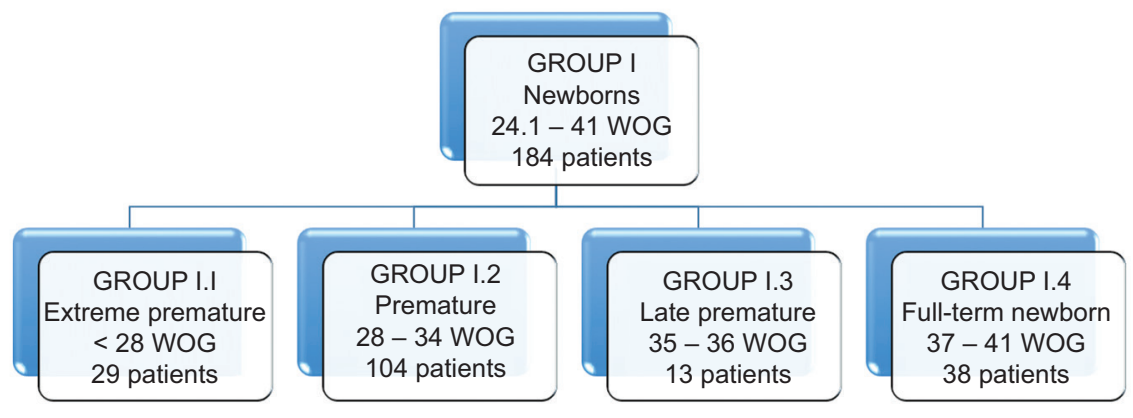

Figure 3. Group I patients distribution by age. WOG: weeks of gestation.

any associated problem, with the most common being found to be sepsis-associated RDS in 49 patients (27\%). Diagnoses included in other problems were dysmorphic syndrome, macrosomia, fortuitous delivery, hypoglycemia, jaundice due to $\mathrm{ABO}$ group incompatibility, polycythemia, left diaphragmatic hernia, duodenal atresia, and anorectal malformation (Fig. 4).
Patient weight ranged from $500 \mathrm{~g}$ to $5 \mathrm{~kg}$ (Fig. 5), and regarding gender, there were 81 girls (44\%) and 103 boys $(56 \%)$.

With regard to pharmacological closure, patients were divided in two groups (Fig. 6):

- Group A: 86 patients (46\%) underwent pharmacological closure based on paracetamol, ibuprofen, 


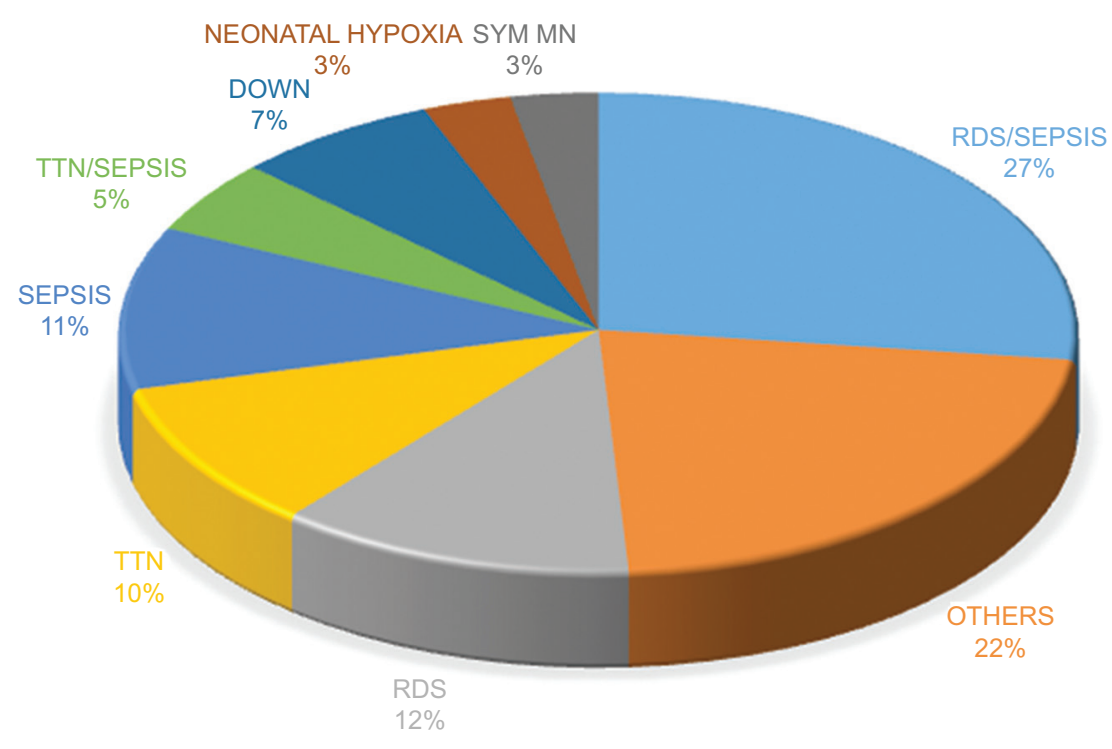

Figure 4. Admission diagnosis in Group I patients. SYM MN: symmetric malnutrition; RDS: respiratory disease syndrome; TTN: transient tachypnea of the newborn.

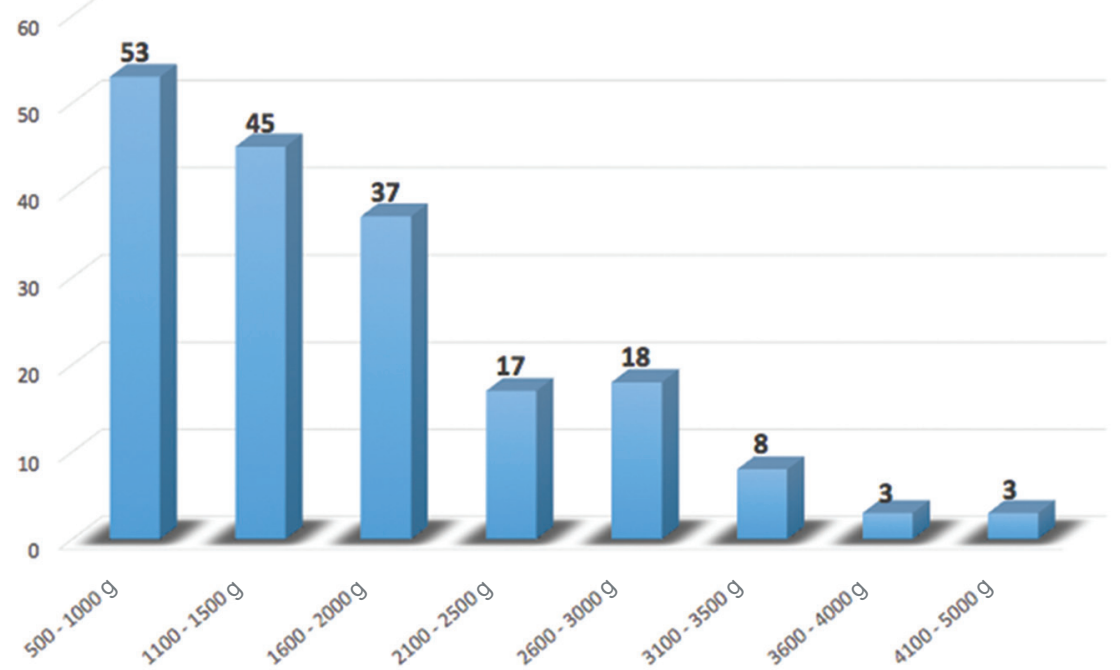

Figure 5. Weight distribution (from $500 \mathrm{~g}$ to $5 \mathrm{~kg}$ ) in Group I patients.

ketoprofen or indomethacin, with a first cycle of 3 days. In case of no echocardiographic response, a second cycle of 3 days was attempted with paracetamol in 29 patients, without closure finally being achieved, and thus they underwent surgery.
- Group B: 98 patients (54\%) had some contraindication for pharmacological closure and went on directly to surgical closure.

One-hundred and two patients (56\%) had some degree of pulmonary hypertension, which in $32(31 \%)$ was mild, in $65(63 \%)$ it was moderate, and in $5(6 \%)$ it was 


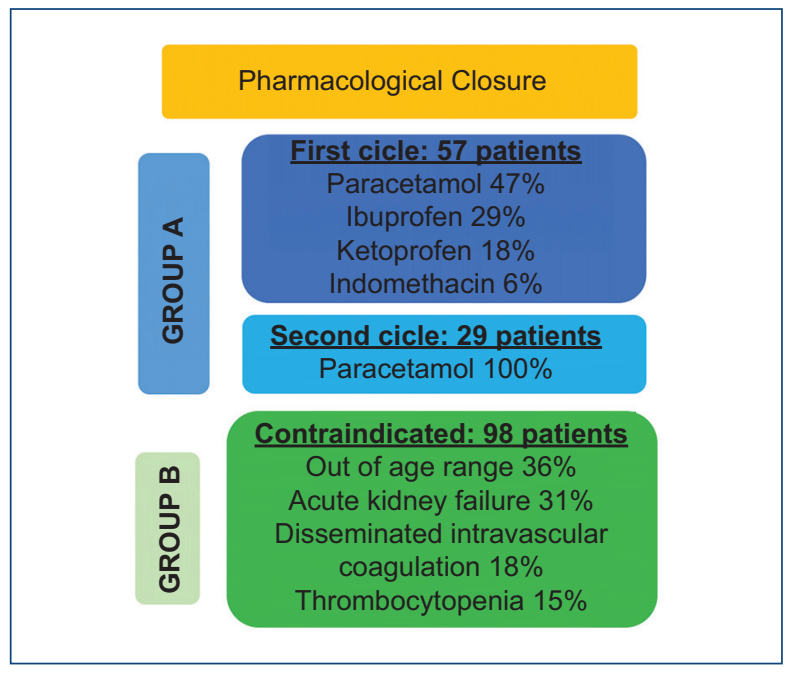

Figure 6. Pharmacological treatment.

severe. Eighty-two patients (44\%) had no pulmonary arterial hypertension.

Of the 184 patients in Group I, 19 (10\%) had associated heart disease: eight (4\%) had ventricular septal defect; $5(3 \%)$, atrial septal defect; $4(2 \%)$, pseudocoarctation off aorta but without significant gradient; and $2(1 \%)$, atrioventricular canal (one of the latter had to be operated on the ductus arteriosus to offer him longer life time and being able to be operated in a tertiary care institution).

In Group I patients, a surgical time of $30-45 \mathrm{~min}$ is reported in $5 \%$ of patients and $45 \mathrm{~min}-1 \mathrm{~h}$ in $28 \%$. Extrapleural approach was the preferred method and was used in 141 patients (77\%).

In patients with PDA, extubation fails due to pulmonary congestion secondary to pulmonary flow increase caused by the ductus arteriosus; therefore, extubation time after surgery was taken as a surgical treatment success parameter, and we found that most patients (59; $32 \%)$ were extubated within the first 5 days, 26 (14\%) at 6-10 days, $10(5.5 \%)$ at $11-15$ days, $3(1.5 \%)$ at 16-20 days, and 8 (4.5\%) after more than 20 days. Twenty-three patients (12.5\%) could not be extubated due to serious complications inherent to their prematurity and admission diagnoses, and they died. The rest, 55 patients $(30 \%)$, were extubated in the operating room (Fig. 7).

Group I complications were present in 33 patients, accounting for $18 \%$ of the NBs. Only $6.5 \%$ had major complications secondary to hemodynamic changes after ductus arteriosus closure: 11 patients (29\%) had pneumothorax that was resolved with the placement of a pleural tube; four (12\%) had non-severe intestinal ischemia that was resolved with intestinal rest and antibiotic therapy; three (9\%) had acute pulmonary edema that was managed with fluid restriction and diuretics; three $(9 \%)$ had pulmonary bleeding; three $(9 \%)$ had cardiogenic shock, managed with amines; two (6\%) had chylothorax that was managed with a pleural tube, fasting, total parenteral nutrition supplemented with medium chain triglycerides, and octreotide; two $(6 \%)$ had diaphragmatic paralysis that was corrected, when their conditions allowed for it, by means of diaphragmatic plication; two (6\%) had surgical wound infection or dehiscence that was resolved with dressing; two (6\%) had residual duct leak observed in the control echocardiogram; and one (3\%) had a tear of the ductus that was repaired on the spot without hemodynamic repercussion (Fig. 8).

Twenty-three patients (12.5\%) died, with the main causes of death being: six $(26 \%)$ due to multiple organ failure, four $(17 \%)$ due to septic shock, three $(13 \%)$ due to neurological sequelae secondary to interventricular hemorrhage, three $(13 \%)$ due to pulmonary hemorrhage, two $(9 \%)$ due to acute pulmonary edema, two $(9 \%)$ due to cardiogenic shock, one $(4 \%)$ due to chylothorax, one (4\%) due to disseminated intravascular coagulation, and one (4\%) due to acute renal failure. None of the deaths occurred during the intraoperative period and it should be noted that the causes of death were inherent to prematurity.

Figure 9 shows age distribution in Group II. The reasons for admission in Group II were: 12 patients with recurrent pneumonia, nine with murmur found on study, six with Down syndrome, six with cyanosis found on study, and five with failure to thrive. In these patients, during their diagnostic approach, the echocardiogram reported the PDA. There were two patients with Marfan syndrome and Alagille syndrome who had PDA and were admitted for surgical correction (Fig. 10).

In Group II, patient weight ranged from 3 to $19 \mathrm{~kg}$ (Fig. 11). As for gender, there were 23 girls (57\%) and 17 boys ( $43 \%)$.

None of the patients in Group II underwent to pharmacological closure because of their age. Twelve patients had some degree of pulmonary hypertension $(30 \%)$, which in two (17\%) was mild, in seven $(58 \%)$ it was moderate, and in three (25\%) it was severe. Twenty-eight patients had no pulmonary arterial hypertension $(70 \%)$.

Of the 40 patients in Group II, only one (2.5\%) had ventricular septal defect as a heart disease associated with PDA. In $82 \%$, extrapleural, in $12 \%$, transpleural, 


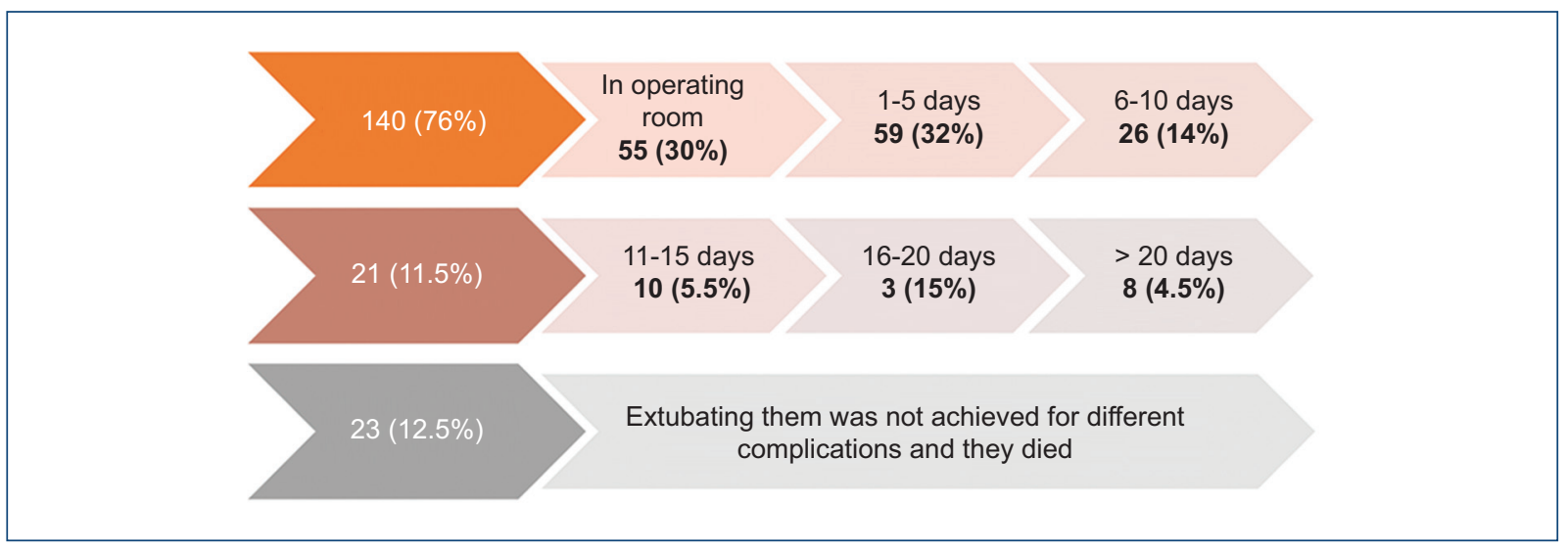

Figure 7. Extubation time as a parameter of success in Group I patients.

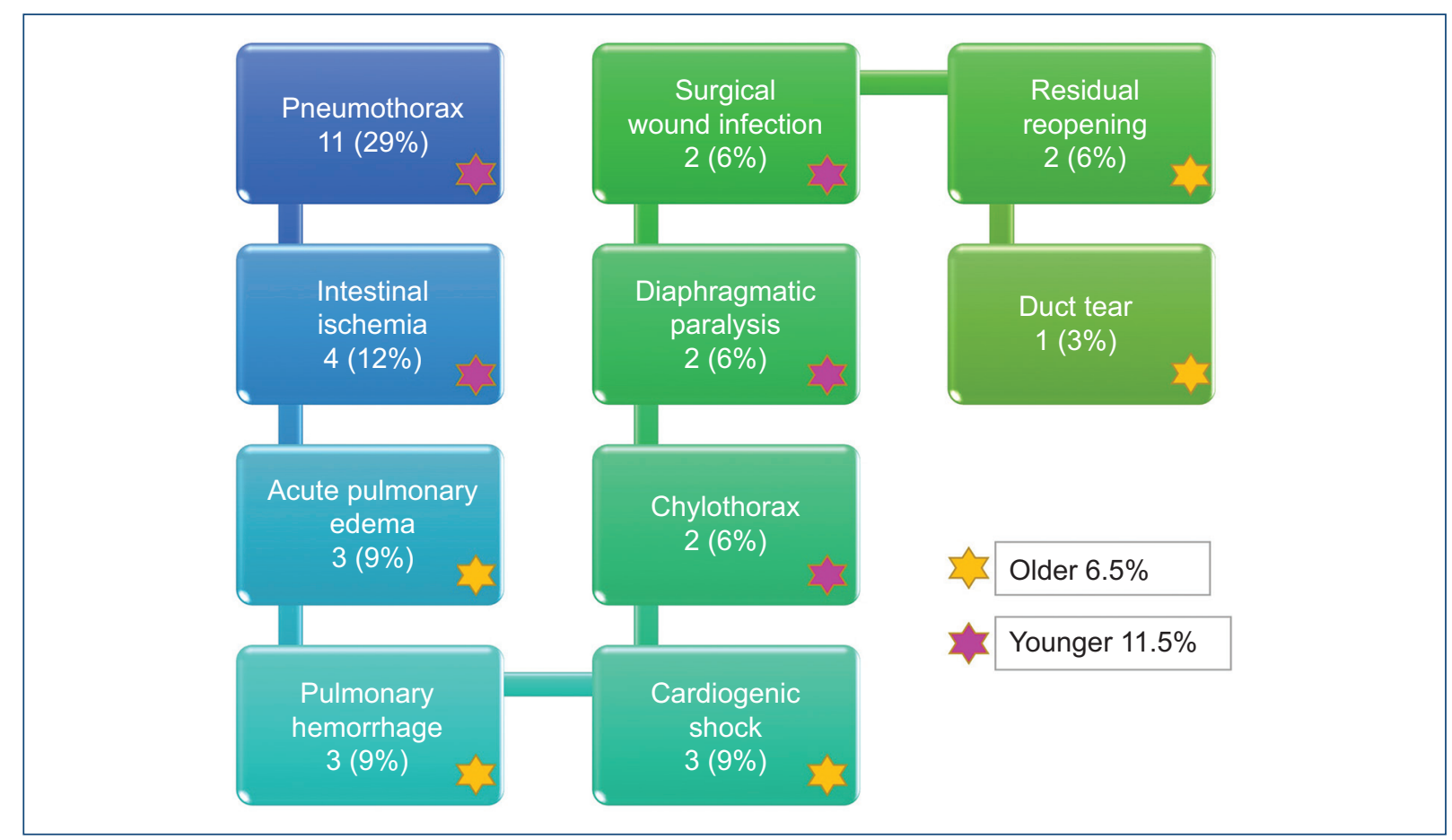

Figure 8. Complications in Group I patients.

and in $6 \%$, thoracoscopic surgical approaches were used.

Extubation time is reported in most patients at the operating room: thirty-four patients (85\%). Of the rest, $4(10 \%)$ were extubated within the first 5 days, one (2.5\%) at 6-10 days, one (2.5\%) at 11-15 days, and one (2.5\%) could not be extubated due to serious complications, and died (Fig. 12). Group II complications are reported in three patients (7.5\%), all of them minor: two patients with pneumothorax that was resolved with the placement of a pleural tube and one patient with surgical wound infection or dehiscence that was resolved with dressing (Fig. 13). In this group of patients, one patient died due to a septic shock that did not respond to intensive hemodynamic management.

\section{Discussion}

In Mexico, there are secondary and tertiary care hospitals that have neonatal intensive care units without 


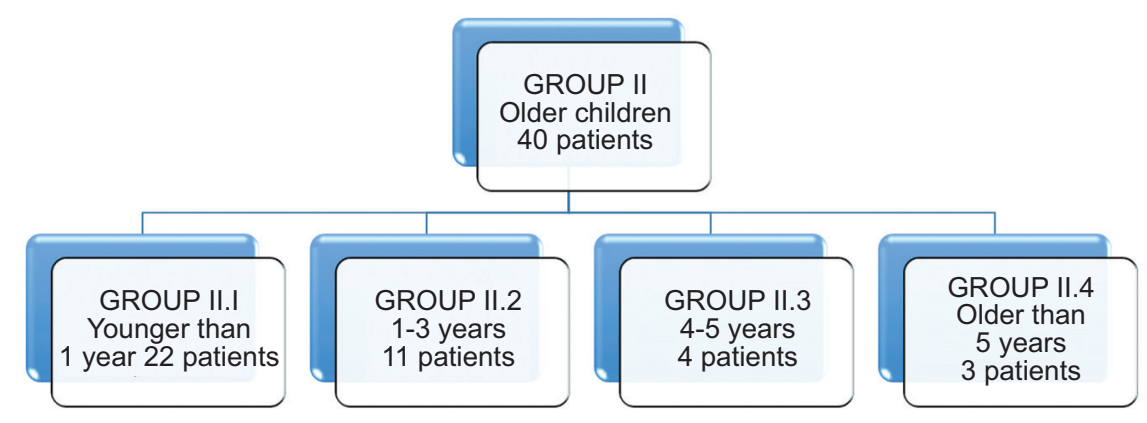

Figure 9. Group II patients age distribution.

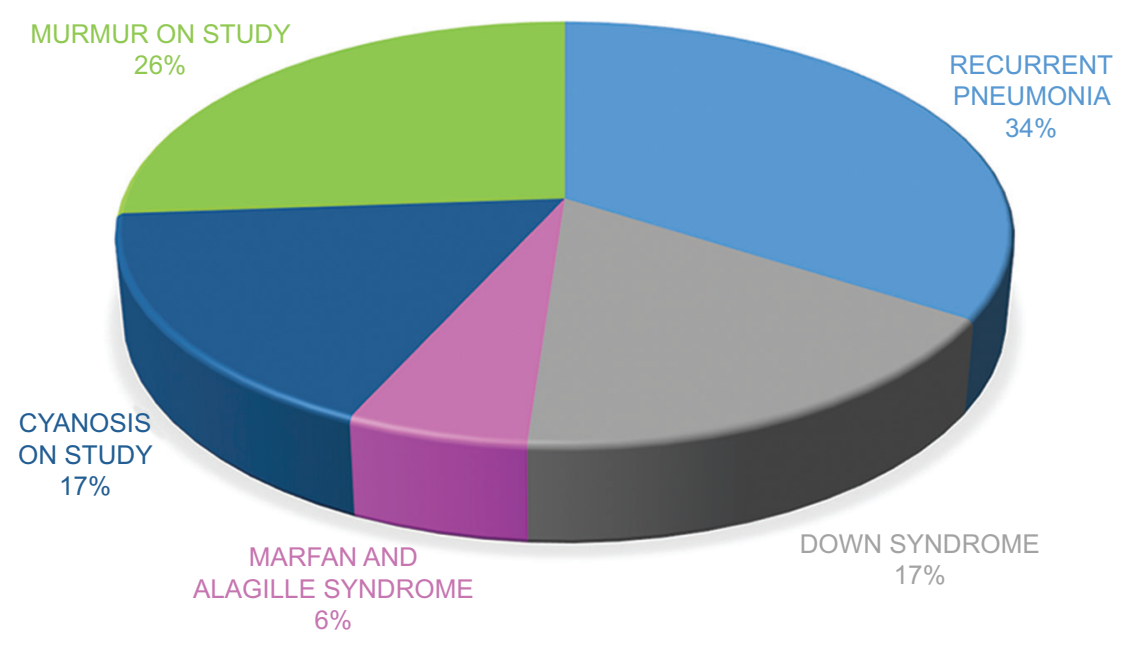

Figure 10. Group II patient's admission diagnosis.

cardiovascular units ${ }^{1-3}$. PDA is the congenital heart disease that is most frequently found in these units, and its resolution is usually attempted by pharmacological closure. Some authors point out a morbidity and mortality of $24 \%$ in patients with surgical closure versus $13 \%$ in those with pharmacological closure ${ }^{17-20}$. However, a variable percentage of NBs with hs-PDA fail to respond to pharmacological closure or have any formal contraindication for trying it; it is in these patients that surgical closure should be performed, and many neonatal intensive care units do not have a pediatric cardiovascular surgeon available.

In this study, we did not analyze the evolution of patients with pharmacological closure, but when this treatment failed or could not be carried out due to any contraindication, we took it as an indicative parameter for surgical closure, and we only analyzed the evolution of patients who underwent surgical correction by a pediatric surgeon.

Although we know that in children weighing more than $2 \mathrm{~kg}$ interventionism for PDA closure is feasible, in most of our units that have intensive neonatal therapy there is no hemodynamic and interventional room available, end neither is there budget for the required devices, and the units that do have the equipment would not be sufficient to provide care to all NBs with hs-PDA.

Complications reported in the literature as attributable to PDA surgery are intraoperative and late post-operative. Intraoperative complications include bleeding 


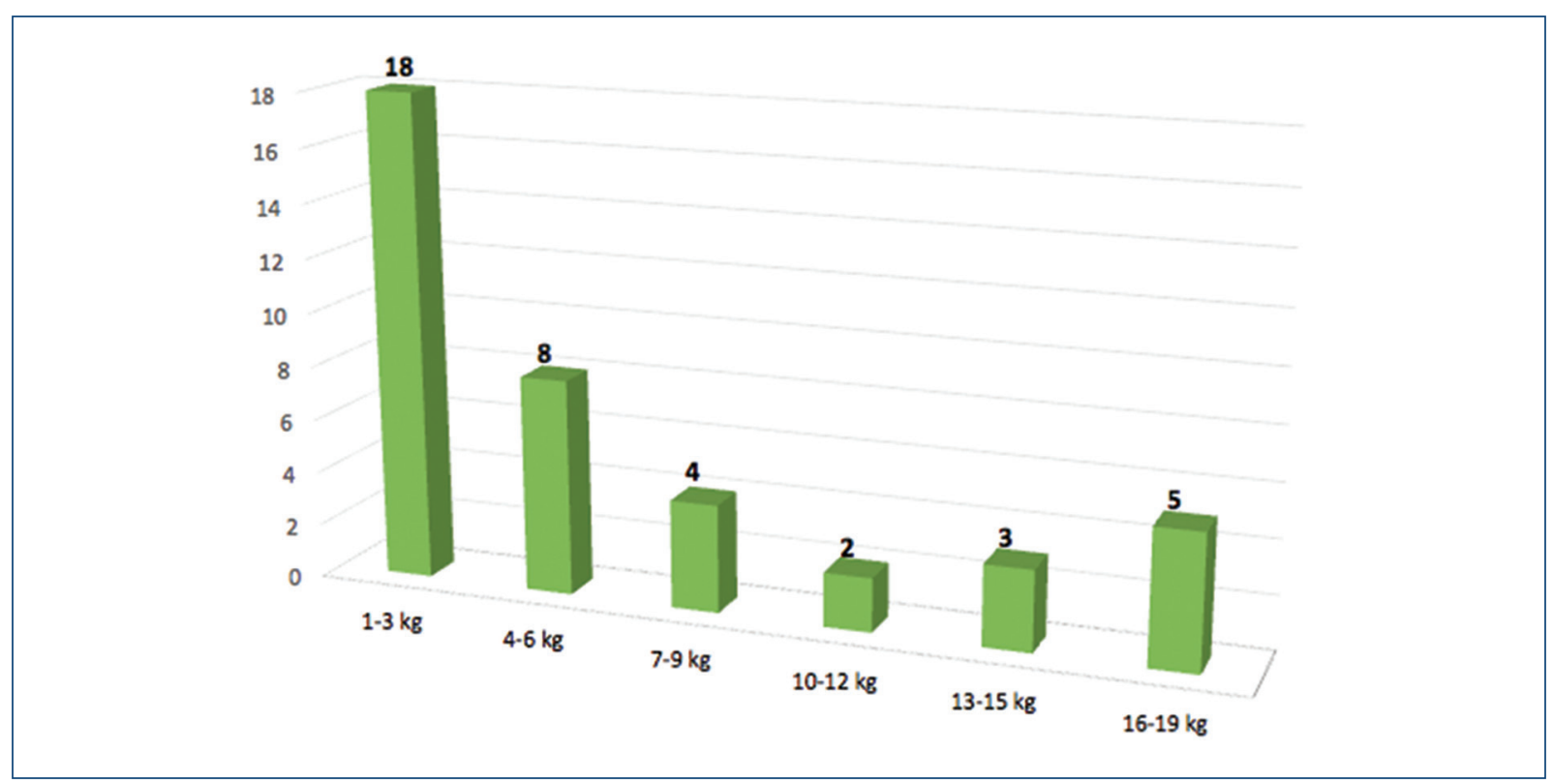

Figure 11. Weight distribution (from 3 to $19 \mathrm{~kg}$ ) in Group II patients.

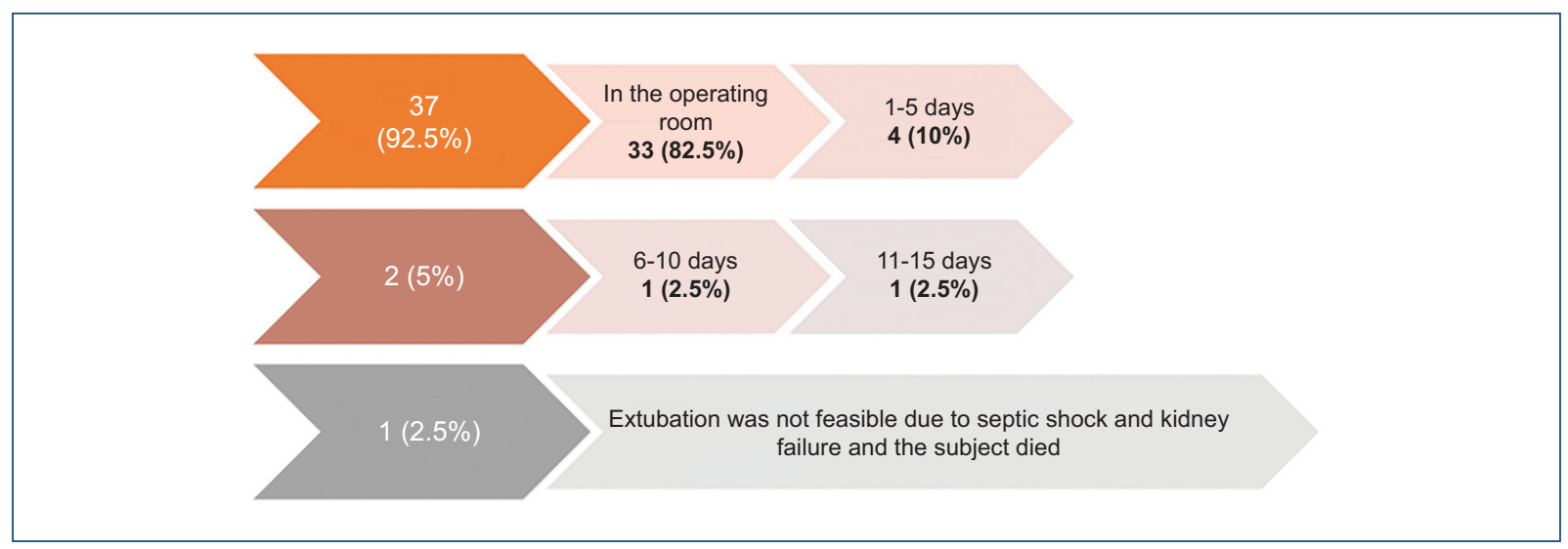

Figure 12. Extubation time as a parameter of success in Group II patients.

or hemorrhage (4-10\%), ductal tear (2-2.5\%), and recurrent laryngeal nerve injury with vocal cord paralysis $(1-8 \%)$. In our study, we only had ductal tear in one case, which represents $0.4 \%$, and was resolved in the operating room without serious complications; in our study, said incident shows a lower incidence than in the reviewed literature. Post-operative complications reported in the literature include pneumothorax (1-13\%), chylothorax (1-4\%), systemic infection $(7-8 \%)$, and wound infection (1-2\%); all present and similar in frequency to those found in our study. Of note, complications in our cases resemble those of the reviewed literature, and most are minor complications that were immediately resolved ${ }^{21-26}$.

PDA surgical closure in our hospital was a very useful option with low morbidity and mortality; therefore, we consider it to be a relatively simple procedure with minimal complications that can be carried out in a secondary care hospital. Our results are highly satisfactory, with an overall survival of $92 \%$.

In our series, mortality was $10.7 \%$ (24 patients), with all deaths being unrelated to the surgical procedure itself.

With this study, we demonstrate the feasibility of these surgeries being performed by a pediatric 


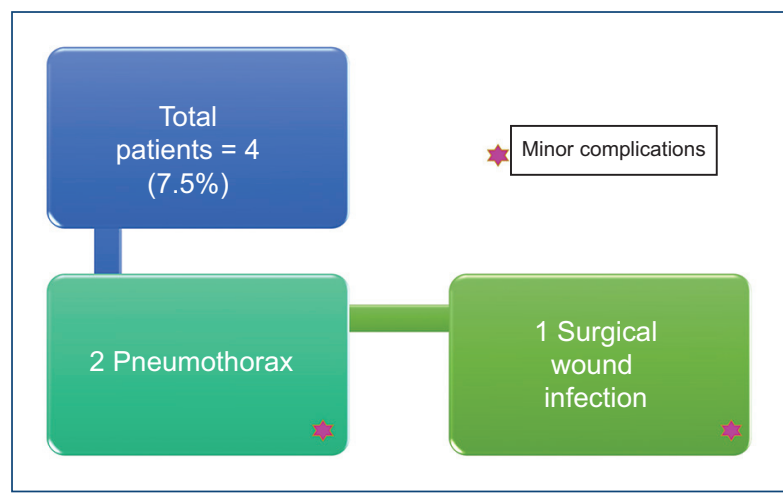

Figure 13. Complications in Group II patients.

surgeon, emphasizing that mortality is comparable to or even lower than that reported in the literature by centers where they do have pediatric cardiovascular surgeons.

\section{Conclusions}

In children's or general hospitals that do not have a pediatric cardiovascular surgery department or a hemodynamics unit for percutaneous closure, PDA surgical closure can be carried out by a pediatric surgeon with experience in this type of interventions. The procedure is safe, easy to perform, reproducible and has minimal complications.

\section{Funding}

None.

\section{Conflicts of interest}

None.

\section{Ethical disclosures}

Protection of human and animal subjects. The authors declare no experiments were performed on humans or animals for this investigation.

Confidentiality of data. The authors declare that no patient data appear in this article. The authors declare that they have followed the protocols of their work center on the publication of patient data.

Right to privacy and informed consent. The authors declare that no patient data appear in this article. The authors have obtained informed consent from the patients and/or subjects referred to in the article.

\section{References}

1. Hermes-DeSatins ER, Clyman RI. Patent ductus arteriosus: pathophysiology and management. J Perinatol. 2006;26:S14-8.

2. Schneider DJ, Moore JW. Patent ductus arteriosus. Circulation. 2006;114:1873-82.

3. Dice JE, Bhatia J . Patent ductus arteriosus: an overview. J Pediatr Pharmacol Ther. 2007;12:138-46.

4. Gallardo-Meza AF, González-Sánchez JM, Piña-Garay MA, Medina-Andrade MA, Cabrera-Rojas $H$, Lozano-Ruiysánchez A, et al. Experiencia en el cierre quirúrgico de ducto arterioso permeable en una unidad de cuidados intensivos (UCIN) de un hospital de segundo nivel en Guadalajara, Jalisco, México. Bol Med Hosp Infan Mex. 2010;67:127-31.

5. DiMenna L, Laabs C, McCoskey L, Seals A. Management of the neonate with patent ductus arteriosus. J Perinat Neonatal Nurs. 2006;20:333-40.

6. Lee HC, Silverman N, Hinz SR. Diagnosis of patent ductus arteriosus by a neonatologist with compact portable ultrasound machine. J Perinatol. 2007:27:291-6.

7. Hammoud MS, Elsori HA, Hanafi EA, Shalabi AA, Fouda IA, Devarajan LV. Incidence and risk factors associated with the patency of ductus arteriosus on preterm infants with respiratory distress syndrome in Kuwait. Saudi Med J. 2003;24:982-5.

8. Costeloe K, Hennessy E, Gibson AT, Marlow N, Wilkinson AR. The EPIcure study: outcome to discharge from hospital for infants born at the threshold of viability. Pediatrics. 2000;106:659-71.

9. Del Moral T, González-Quintero VH, Claure N, Vanbuskirk S, Bancalari E. Antenatal exposure to magnesium sulfate and the incidence of patent ductus arteriosus in extremely low birth weight infants. J Perinatol. 2007; 27:154-7.

10. Klukopw M, Evans N. Early echocardiographic prediction of symptomatic patent ductus arteriosus in preterm infants undergoing mechanical ventilation. J Pediatr. 1995;127:774-9.

11. Evans N, Malcolm G, Osborn D, Kluckow M. Diagnosis of patent ductus arteriosus in preterm infants. Neoreviews. 2004;45:86-97.

12. Laughon MM, Simmons MA, Bose CL. Patency of ductus arteriosus in the premature infant: is it pathologic? Should it be treated? Curr Opin Pediatr. 2004;16:146-51.

13. Peña-Juárez RA, Medina-Andrade MA, Martínez-González MT, Gallardo-Meza AF, Cortez-Comparan D, Piña-Garay MA. Cierre de conducto arterioso con paracetamol: estudio piloto. Rev Esp Cardiol. 2015; 68:441-51.

14. Bökenkamp R, DeRuiter MC, Van-Munsteren C, Gittenberger-de-Groot AC. Insights into the pathogenesis and genetic background of patency of the ductus arteriosus. Neonatology. 2010;98:6-17.

15. Ohlsson A, Shah PS. Paracetamol (acetaminophen) for patent ductus arteriosus in preterm or low birth weight infants. Cochrane Database Syst Rev. 2018;(4):1-116.

16. Galas MO, Hussain A, Arfi AM. Do we still need the surgeon to close the persistently patent arterial duct? Cardiol Young. 2006;16:522-36.

17. Kabra NS, Schmidt B, Roberts RS, Doyle LW, Papile L, Fanaroff A. Neurosensory impairment after surgical closure of patent ductus arteriosus in extremely low birth weight infants: results from the trial of indomethacin prophylaxis in preterms. J Pediatr. 2007;15:229-34.

18. Koehene PS, Bein G, Alexi-Meskhishvili V, Ewng Y, Burher C, Obladen M. Patent ductus arteriosus in very low birthweight infants; complications of pharmacological and surgical treatment. Perinat Med. 2001;29:327-34.

19. Merrit TA, DiSessa TG, Feldman BH, Kirkpatrick SE, Gluck L, Friedman WF. Closure of patent ductus arteriosus with ligation and indomethacin: a consecutive experience. J Pediatr. 1978;93:639-46.

20. Mehmet-Yekta O, Sadik Y, Omer E, Nurdan U, Nahide A, Serife-Suna O, et al. Oral paracetamol versus oral ibuprofen in the management of patent ductus arteriosus in preterm infants: a randomized controlled trial. J Pediatr. 2014;164:510-4

21. Coster DD, Gorton ME, Grooters RK, Thieman KC, Schneider RF, Soltanzadeh $\mathrm{H}$. Surgical closure of the patent ductus arteriosus in the neonatal intensive care unit. Ann Thorac Surg. 1989;48:386-9.

22. Davis JT, Baciewicz FA, Suriyapa S, Vauthy P, Polamreddy R, Barnett B. Vocal cord paralysis in premature infants undergoing ductal closure. Ann Thorac Surg. 1988;46:214-5.

23. Mosalli R, AIFaleh K, Pases B. Role of prophylactic surgical ligation of patent ductus arteriosus in extremely low birth weight infants: systematic review and implications for clinical practice. Ann Pediatr Card. 2009;2: 120-6.

24. Cassady CD, Kirklin JW. A randomized, controlled trial of very early prophylactic ligation of the ductus arteriosus in babies who weighed 1000 gr or less at birth. N Engl J Med. 1989;320:1511-6.

25. Moin F, Kennedy KA, Moya FR. Risk factors predicting vasopressor use after patent ductus arteriosus ligation. Ann Thorac Surg. 1996;61:814-6.

26. Zbar RI, Chen AH, Behrendt DM, Bell EF, Smith RJ. Incidence of vocal cord paralysis in infants undergoing ligation of patent ductus arteriosus. Ann Thorac Surg. 1996;61:814-6. 